\section{(อ) OPEN ACCESS}

\title{
Sore throat turned to be a bronchogenic carcinoma with superior vena cava syndrome
}

\author{
Amr Elmoheen 이, ${ }^{1}$ Mahmoud Eltawagny, ${ }^{1}$ Ahmed Elmesery, ${ }^{2}$ Khalid Bashir ${ }^{1}$
}

${ }^{1}$ Emergency Department, Hamad Medical Corporation, Doha, Qatar

${ }^{2}$ Radiology Department, Sultan Qaboos Hospital, Salalah, Oman

Correspondence to

Dr Amr Elmoheen;

Aelmoheen@hamad.qa

Accepted 11 November 2019

A Check for updates

(c) BMJ Publishing Group Limited 2019. Re-use permitted under CC BY-NC. No commercial re-use. See rights and permissions. Published by BMJ.

To cite: Elmoheen $\mathrm{A}$ Eltawagny $\mathrm{M}$, Elmesery $\mathrm{A}$ et al. BMJ Case Rep

2019:12:e231738

doi:10.1136/bcr-2019-

231738

\section{SUMMARY}

Superior vena cava (SVC) syndrome is a group of symptoms caused by complete or partial obstruction of the flow of blood through the SVC. The obstruction is, in most cases, caused by the formation of thrombus or infiltration of a tumour through the vessel wall. The result is venous congestion that creates a clinical situation relating to increase in the venous pressure in the upper part of the body. Symptoms commonly associated with vena cava syndrome include cough, dyspnoea, swelling of the neck, face and the upper extremities and dilation of the chest vein collaterals. In this paper, we examine the case of a 50-year-old man who presented to the emergency department with 'sore throat' which can be easily misdiagnosed as a case of uncomplicated acute pharyngitis. It was a real challenge to diagnose our patient as SVC syndrome caused by bronchogenic carcinoma.

\section{BACKGROUND}

As a rare presentation of superior vena cava (SVC) syndrome, sore throat was the chief complaint of the patient. Sore throat, which is a prevalent symptom in the emergency department, becomes a challenge to diagnose a case with bronchogenic carcinoma.

\section{CASE PRESENTATION}

The affected patient was a 50-year-old man. Examination of his medical history showed that he was previously healthy with no record of chronic diseases. He also had no allergies but was a chronic smoker. On the first presentation to the primary health centre, he had a sore throat, a change of voice and a mild cough. He received a course of amoxicillin and the cough improved.

The patient later developed puffiness of the neck and face and shortness of breath, mostly at night. He was admitted to a private clinic where he received another course of antibiotics. However, this treatment did not yield any improvement. He then presented to the emergency department of this facility with the sore throat, a puffy face (figure 1), swelling of the neck and shortness of breath. He denied bleeding and vomiting, fever, neck pain, syncope and seizure. He also denied palpitation, chest pain, dizziness, abdominal pain, diarrhoea and dysuria. He had no contact with sick animals or patients.

Physical examination of the patient showed an appearance of wellness and anxiety. He was vitally stable with temperature $38^{\circ} \mathrm{C}$, pulse 106 beats/min, respiratory rate was 21 breath/min and $\mathrm{O} 2$ saturation of $99 \%$ on room air. There was mild puffiness of the face and mild left periorbital oedema. $\mathrm{He}$ had no drooling of saliva, stridor, nasal congestion, conjunctivitis, oral ulcer or a viral exanthem. He had no bulging of the pharyngeal wall, soft palate, or floor of the oropharynx. He had no neck pain, crepitus, trismus or stiff neck. He had no pharyngeal oedema, tonsillar exudates, cervical lymphadenitis or strawberry tongue.

There were enlarged tortuous superficial veins over the chest wall (figure 2). He was fully conscious and had no neurological deficit. His cardiovascular and respiratory system examination were normal. Bedside point-of-care ultrasound showed normal cardiac contractility, no pericardial effusion and no right-sided heart dilatation. The inferior vena cava was mildly dilated.

\section{INVESTIGATIONS}

His complete blood count did not show anaemia or leukocytosis. His blood investigations, including electrolytes, renal and liver functions, were within normal limits.

Chest X-ray showed an enlargement of right hilum with added density within it representing a hilar mass. There is also an ill-defined perihilar opacity noticed on the right side and a widening of the right paratracheal stripe (figure 3 ).

CT thorax, abdomen and pelvis with contrast showed a large lobulated mediastinal mass, with extension to the right hilum, measuring $8 \times 9 \times 8 \mathrm{~cm}$ in anteroposterior (AP), transverse and craniocaudal (CC) dimensions, respectively, showing minimal enhancement (figure 4). The mass lesion was compressing the SVC, causing occlusion of the right main pulmonary artery and partial occlusion of the right upper lobe bronchus. The CT (video 1) showed features were in keeping with a neoplastic process, likely central bronchogenic carcinoma with lymphadenopathy.

The right supraclavicular lymph node incisional biopsy was done. It showed lymph node tissues that were heavily infiltrated by the tumor cells, which were arranged in vague trabeculae and clusters and characterized by significant molding, nuclear hyperchromasia, inconspicuous nucleoli, frequent mitotic figures, and apoptotic bodies. Areas of geographic necrosis were also seen. The diagnosis of a metastatic small cell carcinoma is confirmed and most likely of lung origin. 


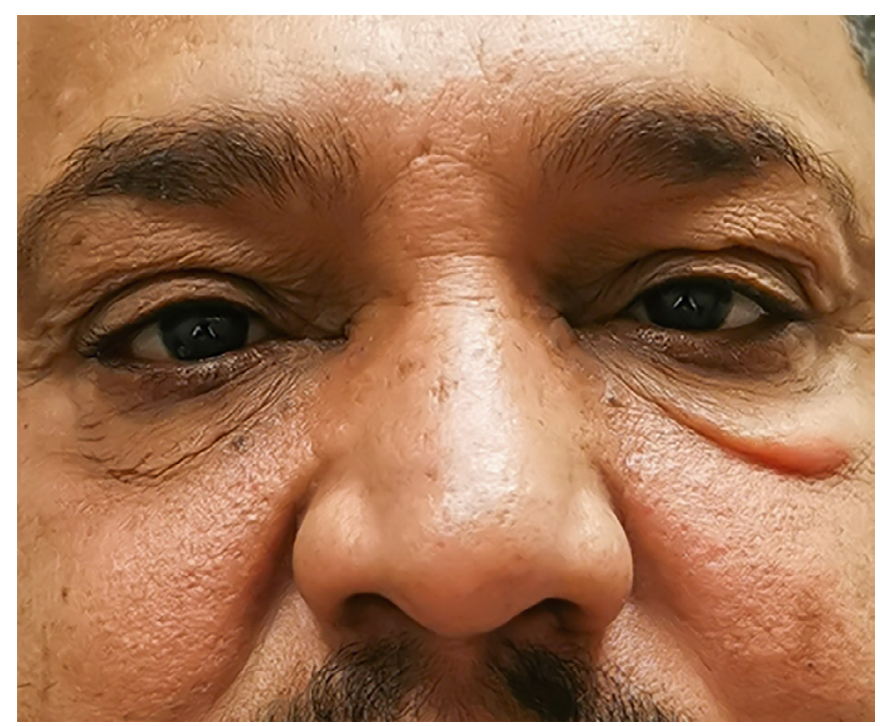

Figure 1 Puffiness of the face and mild periorbital oedema.

\section{DIFFERENTIAL DIAGNOSIS}

The patient presented to the emergency department with 'sore throat,' which can be easily misdiagnosed as a case of uncomplicated acute pharyngitis. He had no local signs of acute pharyngitis like pharyngeal oedema, uvular oedema, patchy tonsillar exudates, cervical lymphadenitis or strawberry tongue. The X-ray of the patient's chest showed an enlargement of the right hilum with added density within it representing hilar mass. A CT of the thoracic, abdominal and pelvic regions with contrast showed the presence of a large lobulated mediastinal mass. The mass lesion was compressing the SVC and the right main pulmonary artery and partially occluded the right upper lobe bronchus. The right supraclavicular lymph node incisional biopsy showed lymph node tissues that were heavily infiltrated by the tumour

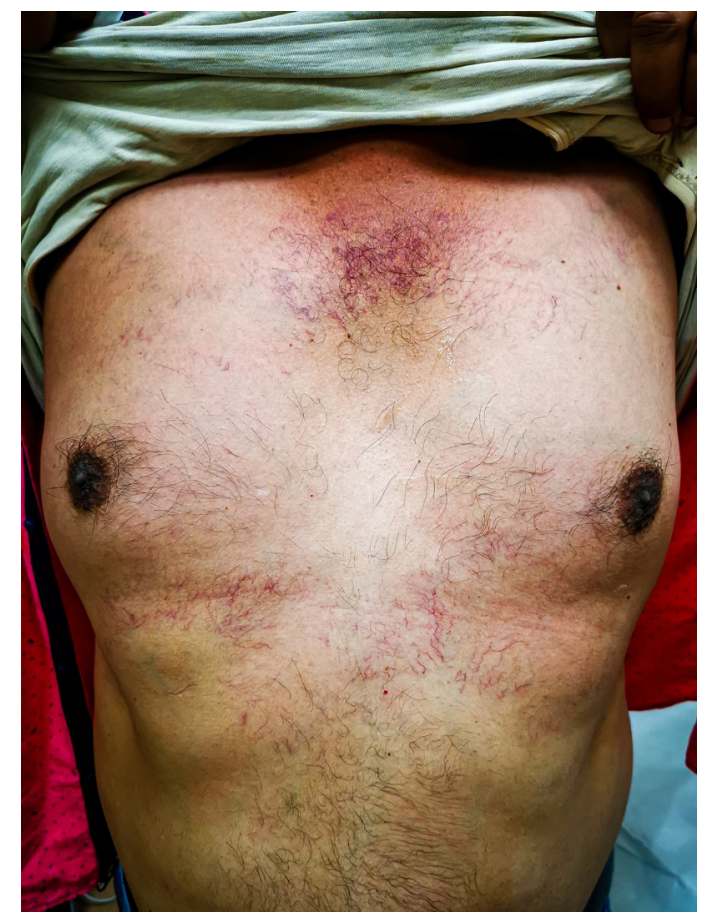

Figure 2 Enlarged and engorged collateral veins.

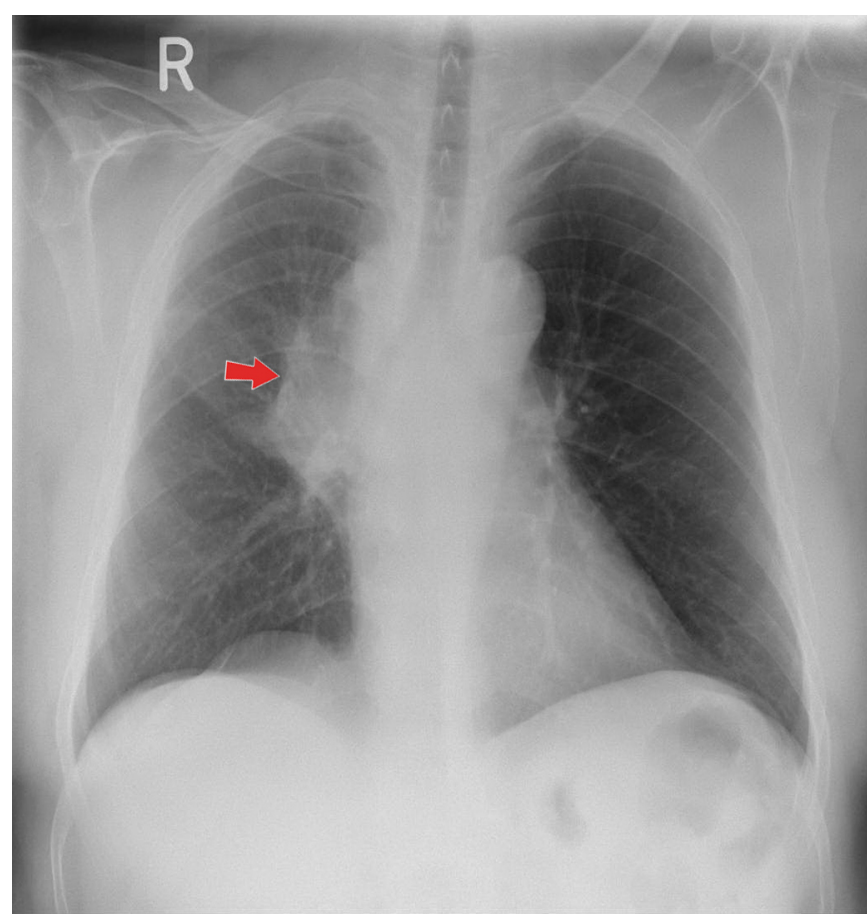

Figure 3 Chest X-ray showing right hilar mass with perihilar opacity (red arrow).

cells. The diagnosis of a SVC syndrome caused by bronchogenic carcinoma was confirmed.

\section{TREATMENT, OUTCOME AND FOLLOW-UP}

After the diagnosis of SVC syndrome caused by bronchogenic carcinoma was confirmed, the multidisciplinary treatment plan was explained to the patient. Unfortunately, he travelled home to start the treatment in his country, and he was lost to follow-up.

\section{DISCUSSION}

Acute pharyngitis accounts for approximately 12 million ambulatory care visits, or 1 to 2 percent of all ambulatory care visits in the USA annually. ${ }^{1}$ That is why it was a real challenge to diagnose our patient as a case of SVC syndrome caused by bronchogenic carcinoma.

'Sore throat' can be explained by oedema that can narrow the lumen of the nose and larynx, possibly jeopardising the function of the larynx or pharynx. Another plausible explanation of sore throat is the congestion of pharyngeal venous plexus due to SVC obstruction. The pharyngeal venous plexus drains into the internal jugular vein, which eventually drains into the SVC. ${ }^{2}$

The main goals in the evaluation of adults with 'sore throat' are the exclusion of severe or potentially life-threatening conditions and the identification of treatable causes.

Our patient had no signs of severe upper airway obstruction like drooling or pooling of saliva, stridor or respiratory distress. He had no toxic appearance, rigours, nasal congestion, conjunctivitis, coryza, oral ulcer or a viral exanthem. He had no deep neck space infections, which can be manifested by a unilateral sore throat, bulging of the pharyngeal wall, soft palate or floor of the oropharynx, neck pain, crepitus, trismus or stiff neck. He had no tonsillar-pharyngeal oedema, uvular oedema, patchy tonsillar exudates, cervical lymphadenitis or strawberry tongue.

SVC syndrome is a disorder whose symptoms are attributed to partial or complete obstruction of the flow of blood within the SVC. Most cases of SVC syndrome are due to an underlying 


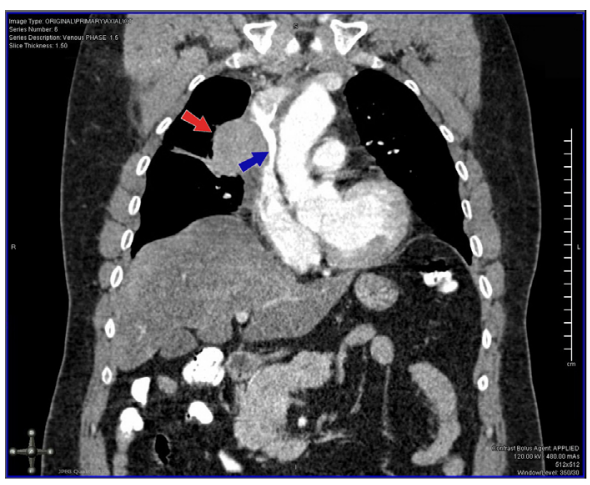

Large mediastinal mass (red arrow) compressing the superior vena cava (blue arrow)

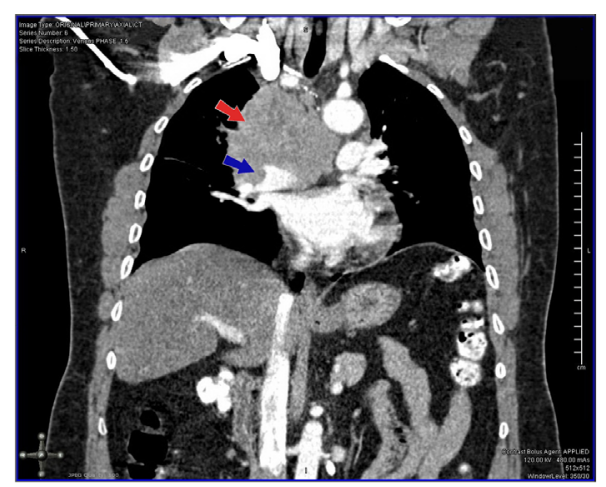

Large mediastinal mass (red arrow) compressing the right main pulmonary artery (blue arrow)

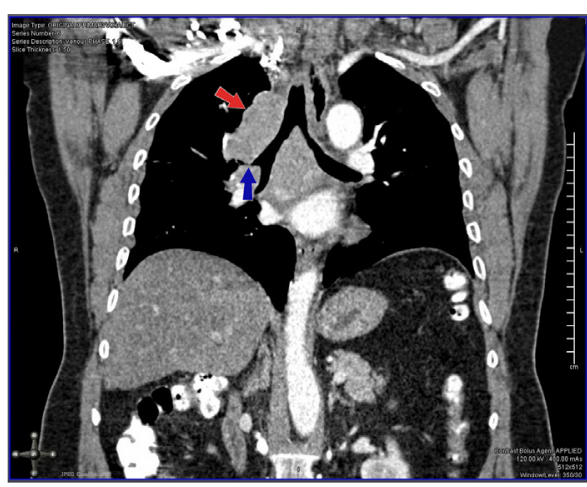

Large mediastinal mass (red arrow) causing partial occlusion of right upper lobe bronchus (blue arrow)

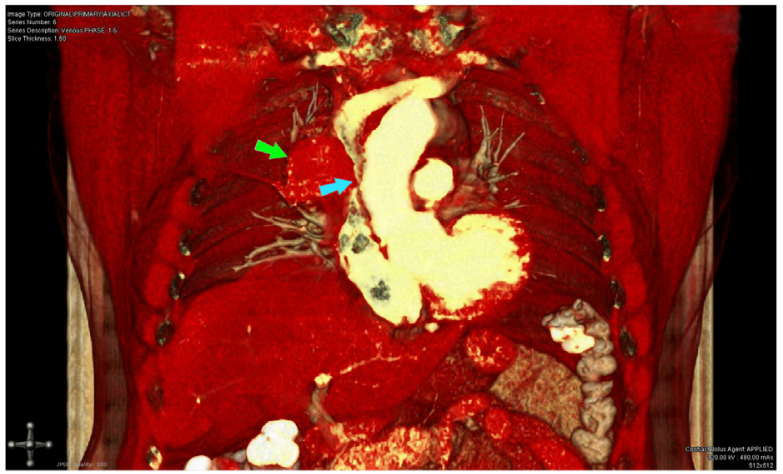

3D view showing a large mediastinal mass (green arrow) compression of the superior vena cava (blue arrow)

Figure 4 CT thorax, abdomen and pelvis with contrast.

disorder; mainly intrathoracic malignancy. Majority of intrathoracic malignancies are due to non-Hodgkin's lymphoma or lung cancer. ${ }^{34}$ SVC syndrome should be considered in patients who present with facial oedema or periorbital oedema. Other clinical representations of SVC syndrome include engorgement of the veins in the chest wall, neck distention, cough, swelling of the arm, and dyspnoea on exertion. SVC syndrome is also indicated by Pemberton's syndrome when the elevation of both arms results in cyanosis and facial congestion. ${ }^{5}$ Confirmatory tests are done by CT scan and tissue histology. These tests are done before the therapy.

After a clinical diagnosis of SVC, there is a need for supportive therapy and management. Supportive treatment involves elevation of the patient's head to reduce venous pressure. The underlying aetiology of the patient's SVC syndrome also guides the management of the condition. Early diagnosis is the key to relieving symptoms of obstruction while prompt treatment will help prevent fatal complications. ${ }^{34}$

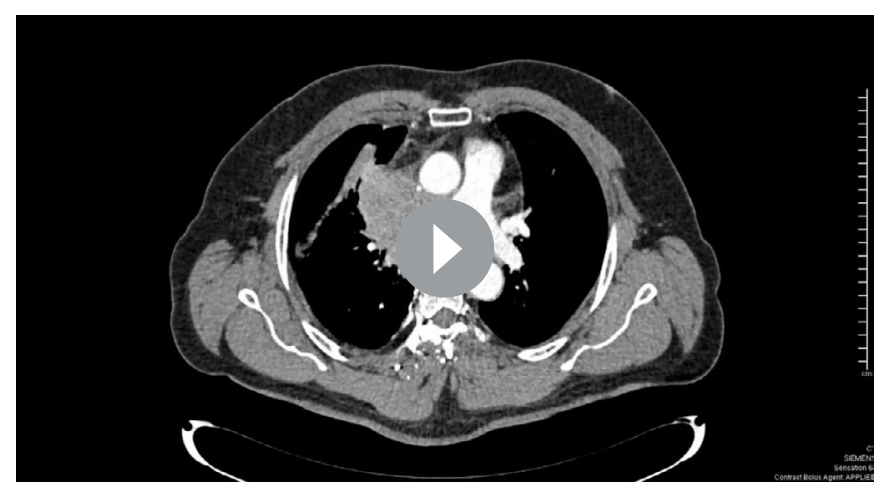

video 1. CT thorax, abdomen and pelvis with contrast.
Treatment of SVC syndrome and its prognosis depends on the underlying cause. The preferred form of treatment is systemic chemotherapy. Thus, the patient in this case study did not need an endovascular stent in the SVC. For less sensitive tumours, the treatment may be a combination of radiotherapy, chemotherapy and/or endovascular stenting. ${ }^{34}$ Endovascular stenting is very useful in the relief of airway obstruction or of the SVC. ${ }^{67}$

It should be noted that most occurrences of SVC syndrome are now linked to an occlusive venous thrombus. This thrombus impedes venous return. The increase in the use of catheters, pacemakers and implantable cardioverter defibrillator (ICD) leads have contributed to this. This results in fibrosis, inflammation of the venous wall, and eventually, stenosis of the SVC. ${ }^{8-10}$

For patients whose thrombus may be due to an indwelling intravascular device, removal should be done together with catheter-directed thrombolysis and anticoagulation therapy.

Our patient had been diagnosed with bronchogenic carcinoma. This has tremendous clinical implications. Patients whose obstruction is attributed to malignancy should undergo multidisciplinary treatment because the tumour type and staging can rightly guide the required radiation therapy or chemotherapy. Surgical repair via bypass grafting with the femoral vein, spiral saphenous vein, dacron graft or polytetrafluoroethylene graft can put the SVC obstruction in check. However, this is mostly used for cases where recanalisation via endovascular repair is impossible or has failed. With a wide range of treatment options covering both malignant and benign aetiology, endovascular therapy now acts as a first-line treatment for SVC syndrome. Patients may get immediate relief from symptoms through less invasive management techniques. ${ }^{11-13}$ 


\section{Patient's perspective}

I had a sore throat for 2 weeks. I thought that I have uncomplicated pharyngitis. I did not notice the red marks over my chest. I was surprised by the diagnosis of lung cancer and obstruction of one of my big veins. I believe that the cause is my heavy smoking for a long time. I appreciate the efforts done by the physicians. I prefer to travel back home to start treatment in my country.

\section{Learning points}

- Sore throat is a common presentation in most emergency departments. The condition can be challenging to diagnose and treat because it is not always easy to get the diagnosis right the first time.

- The physician should keep a high index of suspicion of other causes of; 'sore throat' especially when there are no local signs of pharyngitis like tonsillar-pharyngeal oedema, uvular oedema, patchy tonsillar exudates, cervical lymphadenitis or strawberry tongue.

- A bronchogenic carcinoma complicated with a superior vena cava (SVC) syndrome can be presented primarily with sore throat. History taking, meticulous physical examination and relevant investigations are the proper way to reach the correct diagnosis.

- Chest X-ray is the accepted first imaging that can show the hilar mass.

- CT chest with contrast is the best imaging to illustrate the actual size of the mass and the compression of the SVC.

Contributors AmE: primary author, manuscript writeup. KB: images, manuscript review. AhE: radiological data, images. ME: manuscript review.

Funding The authors have not declared a specific grant for this research from any funding agency in the public, commercial or not-for-profit sectors.

Competing interests None declared.
Patient consent for publication Obtained.

Provenance and peer review Not commissioned; externally peer reviewed.

Open access This is an open access article distributed in accordance with the Creative Commons Attribution Non Commercial (CC BY-NC 4.0) license, which permits others to distribute, remix, adapt, build upon this work non-commercially, and license their derivative works on different terms, provided the original work is properly cited and the use is non-commercial. See: http://creativecommons.org/ licenses/by-nc/4.0/.

\section{ORCID iD}

Amr Elmoheen http://orcid.org/0000-0002-5079-5353

\section{REFERENCES}

1 Schappert SM, Rechtsteiner EA. Ambulatory medical care utilization estimates for 2006. Natl Health Stat Report 2008;8:1-29.

2 Rice TW, Rodriguez RM, Light RW. The superior vena cava syndrome: clinical characteristics and evolving etiology. Medicine 2006;85:37.

3 Wilson LD, Detterbeck FC, Yahalom J. Clinical practice. superior vena cava syndrome with malignant causes. N Eng/ J Med 2007;356:1862-9.

4 Drews RE, Rabkin DJ. Malignancy-related superior vena cava syndrome-UpToDate. Available: http://www.uptodate.com/contents/malignancy-related-superior-vena-cavasyndrome [Accessed 26 May 2019]

5 Anders H, Keller C. Pemberton's maneuver - a clinical test for latent superior vena cava syndrome caused by a substernal mass. Eur J Med Res 1997;2:488-90.

6 Nicholson AA, Ettles DF, Arnold A, et al. Treatment of malignant superior vena cava obstruction: metal stents or radiation therapy. J Vasc Interv Radiol 1997;8:781-8.

7 Lanciego C, Pangua C, Chacón Jl, et al. Endovascular stenting as the first step in the overall management of malignant superior vena cava syndrome. AJR Am J Roentgenol 2009;193:549-58.

8 Kalinin RE, Suchkov IA, Shitov II, et al. [Venous thromboembolic complications in patients with cardiovascular implantable electronic devices]. Angio/ Sosud Khir 2017;23:69-74.

9 Ghorbani H, Vakili Sadeghi M, Hejazian T, et al. Superior vena cava syndrome as a paraneoplastic manifestation of soft tissue sarcoma. Hematol Transfus Cell Ther 2018:40:75-8.

10 Labriola L, Seront B, Crott R, et al. Superior vena cava stenosis in haemodialysis patients with a tunnelled cuffed catheter: prevalence and risk factors. Nephrol Dial Transplant 2018;33:2227-33.

11 Nossair F, Schoettler P, Starr J, et al. Pediatric superior vena cava syndrome: an evidence-based systematic review of the literature. Pediatr Blood Cancer 2018:65:e27225.

12 lerardi AM, Jannone ML, Petrillo M, et al. Treatment of venous stenosis in oncologic patients. Future Oncol 2018;14:2933-43.

13 Kalra M, Sen I, Gloviczki P. Endovenous and operative treatment of superior vena cava syndrome. Surg Clin North Am 2018;98:321-35.

Copyright 2019 BMJ Publishing Group. All rights reserved. For permission to reuse any of this content visit

https://www.bmj.com/company/products-services/rights-and-licensing/permissions/

BMJ Case Report Fellows may re-use this article for personal use and teaching without any further permission.

Become a Fellow of BMJ Case Reports today and you can:

- Submit as many cases as you like

- Enjoy fast sympathetic peer review and rapid publication of accepted articles

- Access all the published articles

- Re-use any of the published material for personal use and teaching without further permission

Customer Service

If you have any further queries about your subscription, please contact our customer services team on +44 (0) 2071111105 or via email at support@bmj.com.

Visit casereports.bmj.com for more articles like this and to become a Fellow 